\title{
Metagenomic and satellite analyses of red snow in the Russian Arctic
}

Nao Hisakawa, Steven Quistad, Eric R Hester, Daria Martynova, Heather Maughan, Enric Sala, Maria V. Gavrilo, Forest Rohwer

Cryophilic algae thrive in liquid water within snow and ice in alpine and polar regions worldwide. Blooms of these algae lower albedo (reflection of sunlight), thereby altering melting patterns (Kohshima et al. 1993; Lutz et al. 2014; Thomas \& Duval 1995). Here metagenomic DNA analysis and satellite imaging were used to investigate red snow in Franz Josef Land in the Russian Arctic. Franz Josef Land red snow metagenomes confirmed that the communities are composed of the autotroph Chlamydomonas nivalis that is supporting a complex viral and heterotrophic bacterial community. Comparisons with white snow communities from other sites suggest that white snow and ice are initially colonized by fungal-dominated communities and then succeeded by the more complex $C$. nivalis-heterotroph red snow. Satellite image analysis showed that red snow covers up to $80 \%$ of the surface of snow and ice fields in Franz Josef Land and globally. Together these results show that $C$. nivalis supports a local food web that is on the rise as temperatures warm, with potential widespread impacts on alpine and polar environments worldwide. 


\section{Metagenomic and Satellite Analyses of Red Snow in the Russian Arctic}

Nao Hisakawa ${ }^{1}$, Steven Quistad ${ }^{1}$, Eric Hester $^{1}$, Daria Martynova ${ }^{2,3}$, Heather Maughan ${ }^{4}$, Enric Sala $^{5}$, Maria Gavrilo ${ }^{3}$, Forest Rohwer ${ }^{1}$

${ }^{1}$ Department of Biology, San Diego State University, 5500 Campanile Drive, San Diego, CA 92182

$1{ }^{2}$ White Sea Biological Station, Zoological Institute, Russian Academy of Sciences,

2 Universitetskaya nab. 1, 199034, St. Petersburg, Russia

3 3National Park "Russian Arctic", pr. Sovetskikh Kosmonavtov, 57, Arkhangelsk, Arkhangelsk

4 Oblast, 163000, Russia

$5 \quad{ }^{4}$ Ronin Institute, Montclair, NJ 07043 USA

$6 \quad{ }^{5}$ National Geographic Society, Washington, DC 20036

*Corresponding author: Heather Maughan, 296 Concession 6E, RR3, Mildmay, ON N0G 2J0 Canada, heathermaughan@gmail.com 


\section{Abstract}

Cryophilic algae thrive in liquid water within snow and ice in alpine and polar regions worldwide. Blooms of these algae lower albedo (reflection of sunlight), thereby altering melting patterns (Kohshima et al. 1993; Lutz et al. 2014; Thomas \& Duval 1995). Here metagenomic DNA analysis and satellite imaging were used to investigate red snow in Franz Josef Land in the Russian Arctic. Franz Josef Land red snow metagenomes confirmed that the communities are composed of the autotroph Chlamydomonas nivalis that is supporting a complex viral and heterotrophic bacterial community. Comparisons with white snow communities from other sites suggest that white snow and ice are initially colonized by fungal-dominated communities and then succeeded by the more complex $C$. nivalis-heterotroph red snow. Satellite image analysis showed that red snow covers up to $80 \%$ of the surface of snow and ice fields in Franz Josef Land and globally. Together these results show that $C$. nivalis supports a local food web that is on the rise as temperatures warm, with potential widespread impacts on alpine and polar environments worldwide.

\section{Introduction}

Chlamydomonas nivalis is an unicellular snow alga that has been detected worldwide within the upper snow layer in polar and alpine regions (Guiry et al. 2014) and is especially abundant in the Arctic pack ice (Gradinger \& Nurnberg 1996). In these harsh environments, C. nivalis has adapted to intense UV exposure by producing astaxanthin, a UV-screening pigment that produces a visible red hue in snow (Gorton \& Vogelmann 2003; Williams et al. 2003). C. nivalis spends most of its growth season in its red colored stage (Gorton \& Vogelmann 2003; Stibal et al. 2007; Williams et al. 2003); this coloration is visible across the snow/ice surface and can reduce albedo to $40 \%$ [c.f., fresh snow albedo of $75 \%$ (Thomas \& Duval 1995)]. The lower albedo increases local temperature, promoting snow and ice melting and increasing the abundance of $C$. nivalis (Thomas \& Duval 1995). Through this positive feedback loop the abundance of $C$. nivalis amplifies snow and ice melting. $C$. nivalis may also contribute to $\mathrm{CO}_{2}$ by fixing carbon. However, if there is a red snow associated heterotrophic viral and microbial community, much of this newly fixed carbon may be released via respiration (Bardgett et al. 2008). C. nivalis-produced dissolved organic carbon (DOC) may also contribute to priming when the melt water washes into the ocean (Geller 1986; Hamer \& Marschner 2002; Madigan et 
al. 1997; van Nugteren et al. 2009) and lead to increased $\mathrm{CO}_{2}$ release.

Satellite images are useful for studying remote or expansive areas that are otherwise difficult to reach and for detecting land surface changes over time. Remote sensing methods using satellite imagery are applied to a wide range of studies including urban expansion (Wang et al. 2014), agricultural land use change (Dong et al. 2015), and glacial retreats (Wei et al. 2014). Many data sets are free, easily accessible, and have adequate resolution for its purpose. Thus, remote sensing provides an ideal tool for quantifying white and red snows at large spatial and temporal extents. Here we describe the use of remote sensing to quantify white and red snows at large spatial and temporal extents. Metagenomic comparisons of white and red snows were also performed to investigate whether these snows differed in their microbial ecology.

\section{Materials and Methods}

Analysis of satellite images: Remote sensing methods were used to estimate abundances of red snow at eleven locations around the world (see Supplementary Methods). Landsat satellite images were acquired from the USGS Earth Explorer site (http://earthexplorer.usgs.gov/) and image analysis methods were adapted from Takeuchi et al. (Takeuchi et al. 2006) as described in the Supplementary Methods. Red to green reflectance band ratios with wavelengths $630-690$ nanometers and 520 - 600 nanometers, respectively, were used to detect red snow in the satellite images. The spectral reflectance of red snow shows that it has higher reflectance in the red band than in the green band, while the spectral reflectance of white snow and ice has higher reflectance in the green band than the red band (Takeuchi et al. 2006). Therefore, red to green reflectance band ratios that are less than 1.0 are more likely to signify white snow or ice while band ratios that are greater than 1.0 are more likely to signify red snow or ice.

ArcGIS version 10.2 was used to calculate the reflectance band ratios. Previous research indicates areas with reflectance band ratios $>1.02$ are bright red when observed in the field (Takeuchi et al. 2006). For this analysis, areas with reflectance band ratios greater than 1.0 were considered to have a significant amount of red snow because such values have been shown to have an algal cell volume of $100 \mathrm{ml} \mathrm{m}^{-2}$ (Takeuchi et al. 2006). Using the positive linear correlation between algal cell volume biomass and reflectance band ratio, it was assumed that the higher the reflectance band ratio, the higher the algal cell volume biomass. With this in mind, the reflectance band ratios were divided into five categories for optimal visualization of various 
levels of concentrations of red snow (Supplementary Table 1 and Figure 1B).

Algal biomass: To estimate the algal biomass for each location, the surface area belonging to each reflectance band ratio category was multiplied by the mean algal biomass of that category. Although the extent of the area of interest is the same for all three images, they have varying amounts of surface area where red snow can exist due to shifts in snow and ice coverage. Therefore, in addition to the total algal biomass, the total area of snow coverage and the percentage of the total area of snow that was covered with different abundances of red algae were calculated. A pixel was categorized as snow if its normalized difference snow index (NDSI) was greater than 0.4 and, to mask out water, if its near-infrared reflectance value was greater than 0.11 (Sibandze et al. 2014). The number of pixels that meet these conditions was multiplied by the area of the pixel to get the total area of ground covered by snow/ice. To calculate the percentage of the total area of snow that is covered with algae, the total area with each algal abundance level was divided by the total area of snow coverage.

Metagenomic sequencing: Permitting for this work was from the Russian Federation (Ministry of Education and Research \#71; June 3, 2013). Red snows were sampled on Nansen Island ("Nansen") and Greely Island ("Greely_1" and "Greely_2”) of Franz Josef Land. Red snow samples were examined with microscopy to confirm the presence of $C$. nivalis based on morphology (Muller et al. 1998). Three red snow samples of $\sim 15$ L were collected, melted, and passed through a $0.22 \mu \mathrm{m}$ sterivex filter. Greely_1 and Greely_2 represent two different sterivex filters that were both extracted from the same homogenized sample. Total DNA was extracted in the field using the Soil DNA Isolation kit with a custom vacuum manifold (Norgen BioTek Corp., cat\# 26560). From the total DNA, a NexteraXT library kit was used to prepare DNA libraries for sequencing on the Illumina MiSeq. The Nansen, Greely_1, and Greely_2 libraries had 135,749 reads, 86,932 reads and 47,507 reads, respectively (see Supplementary Table 2 for MG-RAST IDs to obtain unfiltered data). Each metagenome was passed through the following quality control pipeline. PrinSeq was used to quality filter reads below $100 \mathrm{bp}$ in length and below an average quality score of 25 , and to remove duplicates and sequence tags (Schmieder \& Edwards 2011b). Reads assigned as human were removed using DeconSeq (Schmieder \& Edwards 2011a). Post quality control, the Nansen library contained 121,455 reads, Greely_1 contained 69,918 reads, and Greely_2 contained 40,344 reads. Seven publicly accessible white snow metagenomes from Svalbard glaciers (a.k.a., 'white snow' throughout manuscript) sampled 
April through June were downloaded from MG-RAST (see Supplementary Table 2 for MGRAST IDs), and reads were quality filtered using the same pipeline as the Franz Josef Land red snow libraries (Maccario et al. 2014). Metagenomes were analyzed using KEGG and M5NR databases within MG-RAST version 3.3 (Meyer et al. 2008). The red snow and white snow libraries were compared to the KEGG database to assign reads to KEGG pathways (e-value < $1 \times 10^{-5} ;>60 \%$ identity; $>15$ aa minimum alignment length). Estimations of taxonomic composition of communities were based on translated comparisons to the non-redundant protein database M5NR (e-value $<1 \times 10^{-5} ;>60 \%$ identity; $>15$ aa minimum alignment length). The dataset was normalized to ensure similar numbers of reads were used for each sample, and then raw read counts were log transformed. Statistical differences between red snow and white snow in the numbers of reads assigned to KEGG pathway groups were identified by ANOVA. Multivariate statistics were performed in R using the vegan (Dixon 2003), clustsig and the stats packages. The adonis function was used to compare metagenome compositions; vegdist was used to generate distance matrices; simprof was used to cluster metagenomes based on similarity; and prcomp was used to perform Principal Component Analysis.

\section{Results and Discussion}

Detection of red snow in a global sample of satellite images: Satellite images with spectral reflectance data were used to approximate snow and ice cover, as well as red algae abundance (Takeuchi 2009; Takeuchi et al. 2006) over several years in Franz Josef Land, as well as eleven other regions of United States, Canada, Greenland, Norway, Austria, India, and New Zealand (Supplementary Figure 1). Red snow was detected at all eleven locations in all the years (Figure 1A). The total area of snow and ice were lowest in the most recent year $(2013,2014$ or 2015, depending on the location; Supplementary Figure 2; Greenland was the exception to this trend). At least $50 \%$ of the total snow/ice area was covered with red algae for the most recent year analyzed (Supplementary Figure 2; exception New Zealand and Franz Josef Land). In seven of the locations, over $80 \%$ of the total snow and ice fields were covered in red algae in the most recent year analyzed (Supplementary Figure 2).

A walking transect from sea level to the glacier on Nansen Island in Franz Josef Land was performed in August 2013 (to be described in a separate manuscript). Therefore, this region was targeted for more detailed analysis. Around and on Nansen, the total red snow algal biomass 
134 increased by $124 \%$ from 1986 to 2002 and by $15 \%$ from 2002 to 2006 , then decreased by $63 \%$

135 from 2006 to 2015 (Figure 1B). These changes in algal cover co-occurred with a total decline in

136 the snow and ice cover (Figure 1B). Visual inspection of the snow and ice on Nansen Island in

137 August of 2013 confirmed the presence of red colored snow and microscopy of red snow

138 samples showed $C$. nivalis cells. Taken together, these results show that even as total snow and

139

140

141

142

143

144

145

146

147

148

149

150

151

152

153

154

155

156

157

158

159

160

161

162

163

164

ice cover declines, red snow cover is still highly prevalent or increasing both in Franz Josef Land and other alpine/polar regions.

Microbes present in white snow and red snow: For metagenomic sequencing, red snow samples were taken from Nansen and Greeley Islands, respectively. Seven white snow metagenomes from Svalbard glaciers were also downloaded and analyzed for comparison (see Methods \& Supplementary Table 2 for MG-RAST ID numbers). The genus-level taxonomic compositions of white snow and red snow were significantly different (ADONIS; F $=4.567 ; \mathrm{p}=$ 0.007). When samples were clustered according to their taxonomical similarities, one red snow sample taken at Greely Island grouped with a Svalbard glacier sample; otherwise the red snow and white snow samples clustered separately (Supplementary Figure 3). This indicates minimal overlap in microbial composition at the genus level.

Community DNA sequences were further compared using multivariate analyses with the top 10 most variable taxa (Supplementary Figure 4). The first two principal components explained $70 \%$ of the between-sample variation in microbial community members. The first principal component described red snow as having higher abundances of species from the bacterial genera Pseudoalteromonas, Alteromonas, Vibrio, and Pedobacter, whereas white snow had higher abundances of species from the eukaryotic genera Aspergillus and Neurospora, as well as the bacterial genera Nostoc, Bacillus and Spirosoma. Red snow had greater overall abundances of Bacteria and viruses (Figure 2A) and a lower abundance of Eukaryotes (Figure $2 \mathrm{~A})$. The bacterial communities associated with red snow have also been observed in an alpine region (Thomas \& Duval 1995) and are probably supported by photosynthate from the C. nivalis. Evidence also suggests that bacterial cells may physically attach to the outer mucilaginous coating of C. nivalis in red snow, forming an arctic holobiont (Remias et al. 2005; Thomas \& Duval 1995).

The metagenomes were also used to verify the presence of Chlamydomonas in snow samples (Supplementary Figure 5). Of the sequence reads assigned to Eukaryotes, the proportion 
165 of reads assigned to the Chlamydomonas-containing phylum Chlorophyta was higher in red 166 snow than white snow (Figure 2B). Conversely, the proportion of reads assigned to the fungal 167 phylum Ascomycota was higher in white snow (Figure 2B). metagenomes were also analyzed for potential metabolic functions. The functions encoded by the red and white snow samples clustered into 8 significant groups, with the red snow samples from Greely and Nansen Islands forming a significant cluster (Supplementary Figure 6). Four white snow samples formed a cluster and the remaining white snow samples clustered individually. Multivariate analysis of the top 10 most variable functions showed that the first two principal components explained $82 \%$ of the variation in the abundances of functional pathways (Supplementary Figure 7). The first component (70\% of the variation) showed that the red snow had higher abundances of genes involved in membrane transport, carbohydrate metabolism, nucleotide and amino acid synthesis/degradation, and energy metabolism. White snow communities were shifted toward cell growth and death, folding sorting and degradation, transcription, transport and catabolism pathways and pathways annotated as important in neurodegenerative diseases (i.e., mitochondrial functions in Eukaryotes).

In order to examine whether microbial communities in red snow encoded completely different functional capabilities from those in snow, the numbers of reads assigned to all KEGG pathways were compared using a matrix of Bray-Curtis dissimilarities. Overall the abundances of level 1 KEGG pathways were not significantly different between red snow and white snow (ADONIS; $F=2.135 ; \mathrm{p}=0.12$ ). However, separate analyses that compared individual pathways (at level 2) between red snow and white snow identified several pathways as significantly different, including pathways related to sugar biosynthesis and metabolism and energy metabolism. Red snow communities had higher abundances of genes that encode lipopolysaccharide biosynthesis and peptidoglycan biosynthesis. Red snow also had a higher proportion of reads assigned to oxidative phosphorylation, methane metabolism, carbon fixation in photosynthetic organisms and carbon fixation pathways (Figure 3B). White snow had higher relative abundances of genes that encode glycan biosynthesis and related pathways such as GPIanchor biosynthesis, other types of O-glycan biosynthesis and various types of N-glycan biosynthesis (Figure 3A).

Taken together, these results support the hypothesis that red snow communities include 
196 primary producers with a large, heterotrophic community including viruses. These red snow

197 communities are photosynthesizing and fixing carbon, and also metabolizing methane, processes

202

203

204

205

206

207 that could accelerate snow melting. In contrast, white snow communities appear to be dominated by fungi, maybe eating refractory organic carbon delivered with the snow (Clarke \& Noone 1985; Rosen et al. 1981; Thevenon et al. 2009). These white snow communities are lacking the signatures of primary productivity.

\section{Conclusions}

Microbiology of snow and ice fields has a long history, including a reference to red snow by Aristotle. However, until now we have not had the tools to determine the full extent and makeup of these communities. Here we use a combination of satellite and metagenomic approaches to show that red snow covers up to $80 \%$ of the examined ice and snow fields. Metagenomics of red snow from Franz Josef Land, one of the most remote polar land masses in the world, show that these communities support a full food web ranging from algae to heterotrophic microbes to viruses. Because of the reduced albedo associated with these communities, red snow creates a positive feedback loop that increases its abundance while simultaneously melting ice and snow (Figure 4). In addition to the direct effects on sunlight absorbance, the heterotrophic activity (including viral lysis) will increase local temperatures. Together, these effects may significantly increase ice and snow melting in the Barents Sea region that is already one of the fastest-warming regions on earth. Projections for global red snow coverage and its influence on warming patterns should be investigated further.

\section{Acknowledgements}

The authors are grateful to Alexander Chichaev, Roman Seliverstov, Pavel Terekhov, Andrew Terekhov, and Sergey Kononov for keeping us alive above water and Dave McAloney for underwater operations. The authors also thank Yuri Gavrilov (INTAARI, St.Petersburg, Russia) and Paul Rose (Royal Geographic Society) for logistical help, as well as the captain and crew of the $\mathrm{M} / \mathrm{V}$ Polaris. 


\section{References}

Bardgett RD, Freeman C, and Ostle NJ. 2008. Microbial contributions to climate change through carbon cycle feedbacks. Isme Journal 2:805-814. DOI 10.1038/ismej.2008.58

Clarke AD, and Noone KJ. 1985. Soot in the Arctic Snowpack - a Cause for Perturbations in Radiative-Transfer. Atmospheric Environment 19:2045-2053. Doi 10.1016/00046981(85)90113-1

Dixon P. 2003. VEGAN, a package of R functions for community ecology. Journal of Vegetation Science 14:927-930. DOI 10.1111/j.1654-1103.2003.tb02228.x

Dong JW, Xiao XM, Kou WL, Qin YW, Zhang GL, Li L, Jin C, Zhou YT, Wang J, Biradar C, Liu JY, and Moore B. 2015. Tracking the dynamics of paddy rice planting area in 1986-2010 through time series Landsat images and phenology-based algorithms. Remote Sensing of Environment 160:99-113. 10.1016/j.rse.2015.01.004

Geller A. 1986. Comparison of Mechanisms Enhancing Biodegradability of Refractory Lake Water Constituents. Limnology and Oceanography 31:755-764.

Gorton HL, and Vogelmann TC. 2003. Ultraviolet radiation and the snow alga Chlamydomonas nivalis (Bauer) Wille. Photochemistry and Photobiology 77:608-615. Doi 10.1562/00318655(2003)077<0608:Uratsa $>2.0 . \mathrm{Co} ; 2$

Gradinger R, and Nurnberg D. 1996. Snow algal communities on Arctic pack ice floes dominated by Chlamydomonas nivalis (Bauer) Wille. Proceedings of the National Institute of Polar Research Symposium on Polar Biology 9:35-43.

Guiry MD, Guiry GM, Morrison L, Rindi F, Valenzuela Miranda S, Mathieson AC, Parker BC, Langangen A, John DM, Barbara I, Carter CF, Kuipers P, and Garbary DJ. 2014. AlgaeBase: an on-line resource for Algae. Cryptogamie Algologie 35:105-115. DOI 10.7872/crya.v35.iss 2.2014 .105

Hamer U, and Marschner B. 2002. Priming effects of sugars, amino acids, organic acids and catechol on the mineralization of lignin and peat. Journal of Plant Nutrition and Soil ScienceZeitschrift Fur Pflanzenernahrung Und Bodenkunde 165:261-268. Unsp [P88/4b]

Doi 10.1002/1522-2624(200206)165:3<261::Aid-Jpln261>3.0.Co;2-I

Kohshima S, Seko K, and Yoshimura Y. 1993. Biotic Acceleration of Glacier Melting in Yala Glacier, Langtang Region, Nepal Himalaya. Snow and Glacier Hydrology 218:309-316.

Lutz S, Anesio AM, Villar SEJ, and Benning LG. 2014. Variations of algal communities cause darkening of a Greenland glacier. Fems Microbiology Ecology 89:402-414. Doi $10.1111 / 1574-6941.12351$

Maccario L, Vogel TM, and Larose C. 2014. Potential drivers of microbial community structure 
and function in Arctic spring snow. Frontiers in Microbiology 5. ARTN 413

DOI 10.3389/fmicb.2014.00413

Madigan MT, Martinko JM, and Parker J. 1997. Brock Biology of Microorganisms: PrenticeHall, Upper Saddle River, NJ.

Meyer F, Paarmann D, D'Souza M, Olson R, Glass EM, Kubal M, Paczian T, Rodriguez A, Stevens R, Wilke A, Wilkening J, and Edwards RA. 2008. The metagenomics RAST server a public resource for the automatic phylogenetic and functional analysis of metagenomes. BMC Bioinformatics 9:386. 10.1186/1471-2105-9-386

Muller T, Bleiss W, Martin CD, Rogaschewski S, and Fuhr G. 1998. Snow algae from northwest Svalbard: their identification, distribution, pigment and nutrient content. Polar Biology 20:1432. DOI $10.1007 / \mathrm{s} 003000050272$

Remias D, Lutz-Meindl U, and Lutz C. 2005. Photosynthesis, pigments and ultrastructure of the alpine snow alga Chlamydomonas nivalis. European Journal of Phycology 40:259-268. Doi $10.1080 / 09670260500202148$

Rosen H, Novakov T, and Bodhaine BA. 1981. Soot in the Arctic. Atmospheric Environment 15:1371-1374. Doi 10.1016/0004-6981(81)90343-7

Schmieder R, and Edwards R. 2011a. Fast Identification and Removal of Sequence Contamination from Genomic and Metagenomic Datasets. Plos One 6. ARTN e17288 DOI 10.1371/journal.pone.0017288

Schmieder R, and Edwards R. 2011b. Quality control and preprocessing of metagenomic datasets. Bioinformatics 27:863-864. DOI 10.1093/bioinformatics/btr026

Sibandze P, Mhangara P, Odindi J, and Kganyago M. 2014. A comparison of Normalised Difference Snow Index (NDSI) and Normalized Difference Principal Component Snow Index (NDPCSI) techniques in distinguishing snow from related land cover types. . South African Journal of Geomatics 3:197-209.

Stibal M, Elster J, Sabacka M, and Kastovska K. 2007. Seasonal and diel changes in photosynthetic activity of the snow alga Chlamydomonas nivalis (Chlorophyceae) from Svalbard determined by pulse amplitude modulation fluorometry. Fems Microbiology Ecology 59:265-273. DOI 10.1111/j.1574-6941.2006.00264.x

Takeuchi N. 2009. Temporal and spatial variations in spectral reflectance and characteristics of surface dust on Gulkana Glacier, Alaska Range. Journal of Glaciology 55:701-709.

Takeuchi N, Dial R, Kohshima S, Segawa T, and Uetake J. 2006. Spatial distribution and abundance of red snow algae on the Harding Icefield, Alaska derived from a satellite image. Geophysical Research Letters 33. Artn L21502

Doi 10.1029/2006g1027819

Thevenon F, Anselmetti FS, Bernasconi SM, and Schwikowski M. 2009. Mineral dust and 
297

298

299

300

301

302

303

304

305

306

307

308

309

310

311

312

313

314

315

elemental black carbon records from an Alpine ice core (Colle Gnifetti glacier) over the last millennium. Journal of Geophysical Research-Atmospheres 114. Artn D17102

$10.1029 / 2008 j \mathrm{j} 011490$

Thomas WH, and Duval B. 1995. Sierra-Nevada, California, USA, Snow Algae - Snow Albedo Changes, Algal Bacterial Interrelationships, and Ultraviolet-Radiation Effects. Arctic and Alpine Research 27:389-399. Doi 10.2307/1552032

van Nugteren P, Moodley L, Brummer GJ, Heip CHR, Herman PMJ, and Middelburg JJ. 2009. Seafloor ecosystem functioning: the importance of organic matter priming. Marine Biology 156:2277-2287. 10.1007/s00227-009-1255-5

Wang L, Wang S, Li W, and Li J. 2014. Monitoring Urban Expansion of the Greater Toronto Area from 1985 to 2014 Using Landsat Images. IEEE International. Quebec City, QC.

Wei JF, Liu SY, Guo WQ, Yao XJ, Xu JL, Bao WJ, and Jiang ZL. 2014. Surface-area changes of glaciers in the Tibetan Plateau interior area since the 1970s using recent Landsat images and historical maps. Annals of Glaciology 55:213-222. 10.3189/2014AoG66A038

Williams WE, Gorton HL, and Vogelmann TC. 2003. Surface gas-exchange processes of snow algae. Proceedings of the National Academy of Sciences of the United States of America 100:562-566. DOI 10.1073/pnas.0235560100 


\section{Figure Legends}

Figure 1. (A) A time series comparison of the percentage of total snow or ice that is covered with algae at selected alpine and polar regions throughout the world, according to data derived from satellite images. (B) A time series comparison of the total area of snow and sea ice, total algal biomass, and percentage of total snow that is covered with algae within the map extent near Nansen Island, Franz Josef Land, for years 1986, 2002, 2006 and 2015. The colored time series shows spatial distribution maps of algal densities of the Nansen Island area in Franz Josef Land.

Figure 2. (A) Abundances of viruses, Bacteria and Eukaryotes in samples from red snow and white snow communities. The y-axis shows abundances after normalizing and standardizing raw read counts to ensure cross-sample comparisons are valid. (B) Bar plots showing abundances of two Eukaryotic phyla found in red snow and white snow communities. Chlorophyta is the phylum that contains the genus Chlamydomonas.

Figure 3. (A) Bar plots showing functional pathways that were statistically significantly different in abundance between red snow and white snow. (B) Bar plots depicting energy metabolism pathways and their abundances in red snow and white snow.

Figure 4. Model of C. nivalis in white and red snows. The left panel shows several microbial communities that are found in white snow. Sunlight promotes astaxanthin expression in $C$. nivalis, turning the snow to red and promoting community metabolism shifts through stimulation of heterotrophic metabolism. The C. nivalis blooms, albedo is decreased and local snow and ice melts at a faster rate (right panel). 


\section{Figure 1 (on next page)}

Changes in red snow through time

(A) A time series comparison of the percentage of total snow or ice that is covered with algae at selected alpine and polar regions throughout the world, according to data derived from satellite images. (B) A time series comparison of the total area of snow and sea ice, total algal biomass, and percentage of total snow that is covered with algae within the map extent near Nansen Island, Franz Josef Land, for years 1986, 2002, 2006 and 2015. The colored time series shows spatial distribution maps of algal densities of the Nansen Island area in Franz Josef Land. 


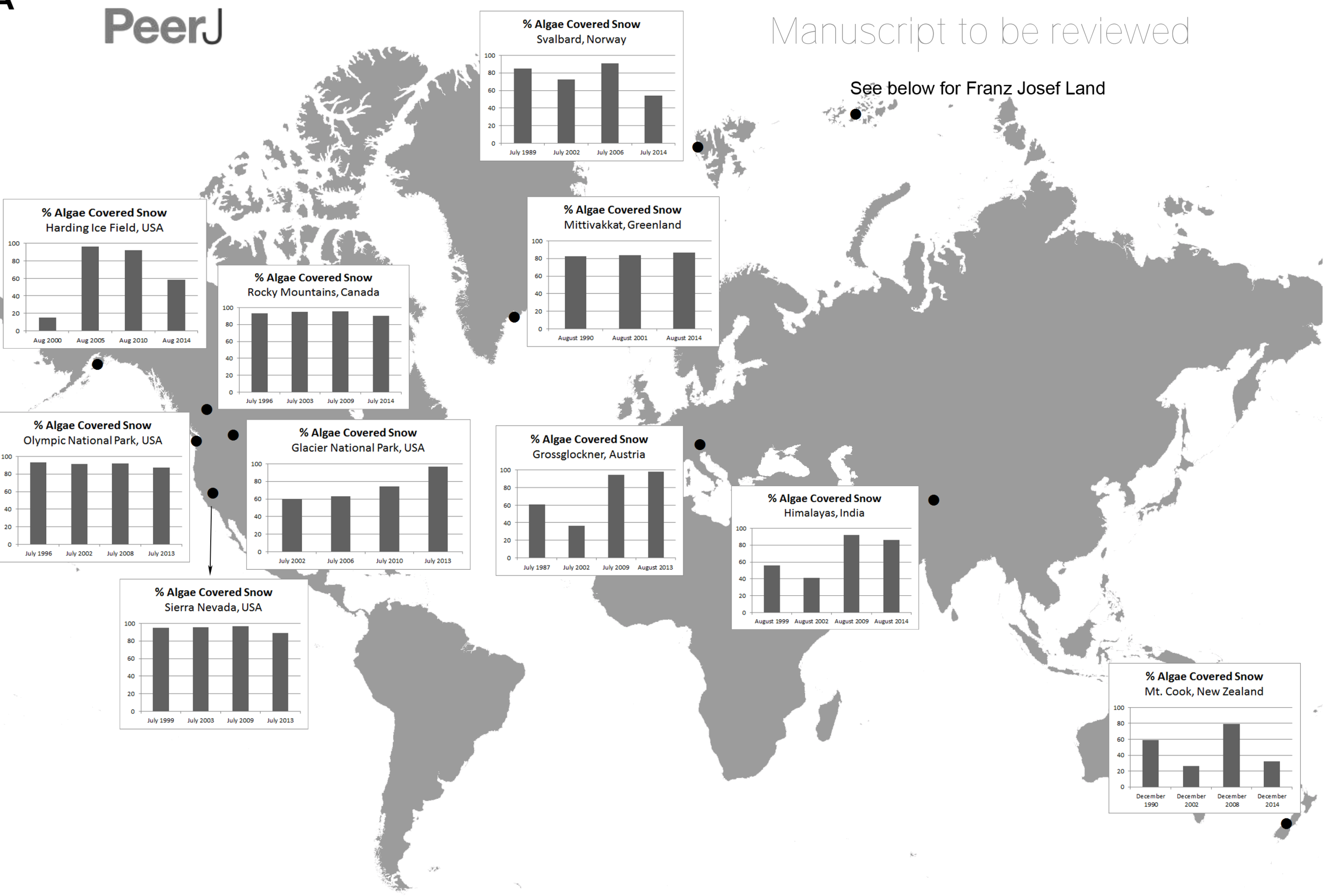

\section{Franz Josef Land}

Algal Biomass $\left(\mathrm{mL} / \mathrm{m}^{2}\right)$

$\square$ White snow or ice

Low (100 - 168.75)

Medium (168.75 - 237.5)

High $(237.5-300)$

Very high $(>300)$

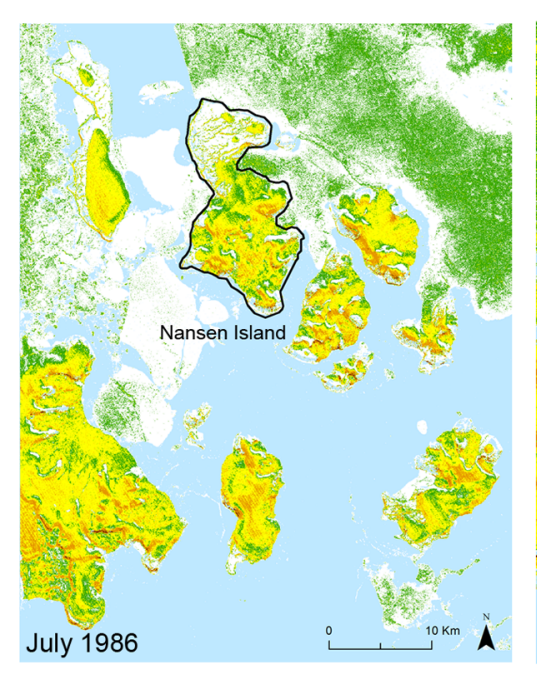

A
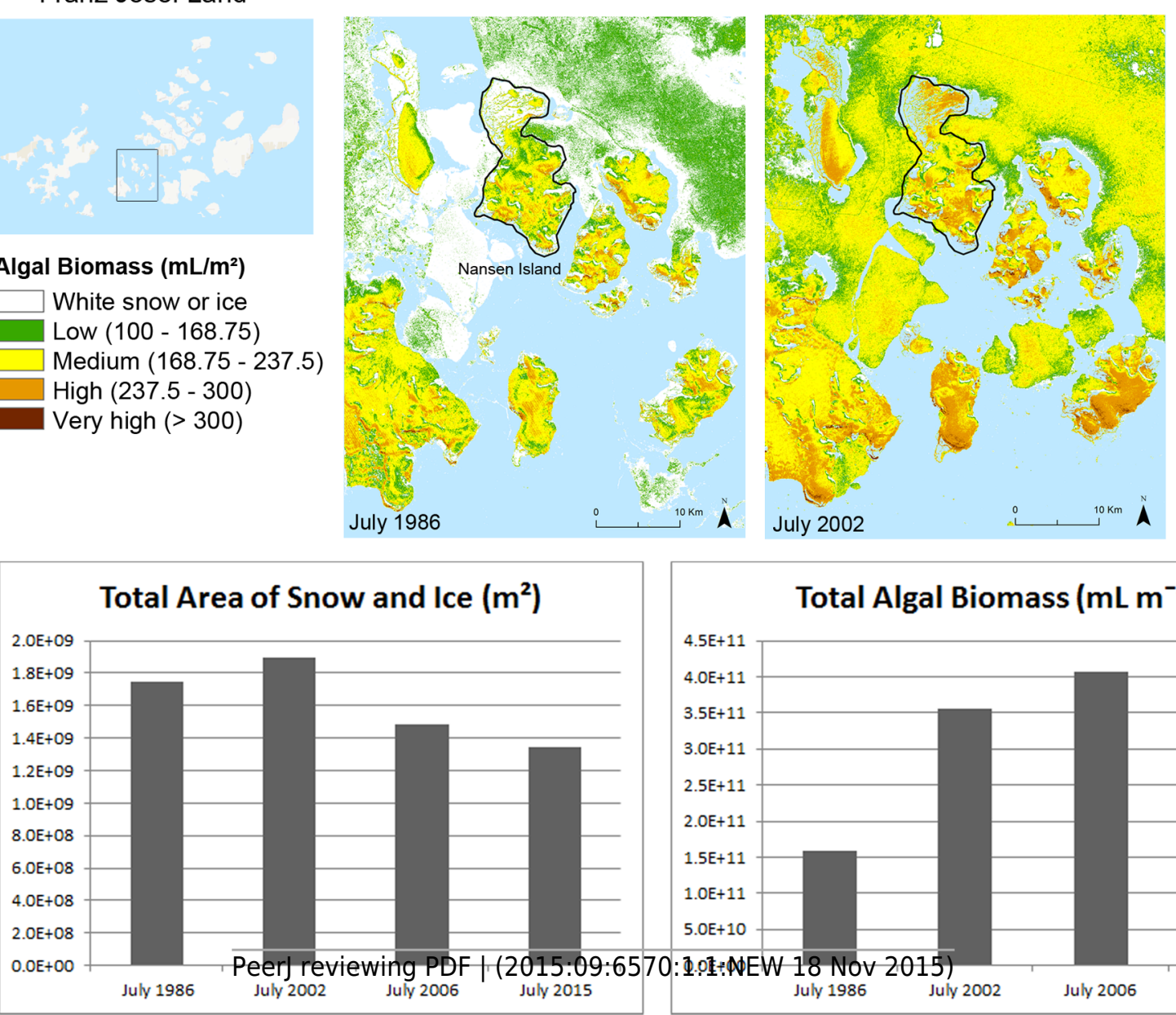

\section{Total Area of Snow and Ice $\left(\mathrm{m}^{2}\right)$}

July 1986
Total Algal Biomass $\left(\mathrm{mL} \mathrm{m}^{-\mathbf{2}}\right)$

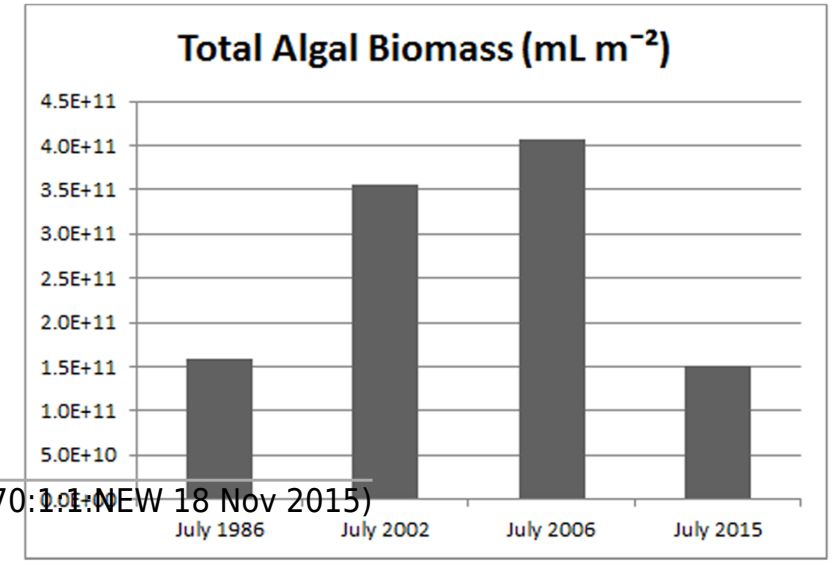

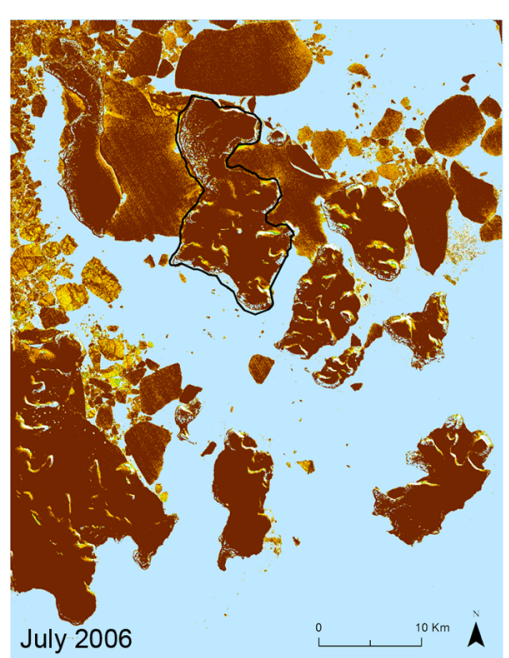

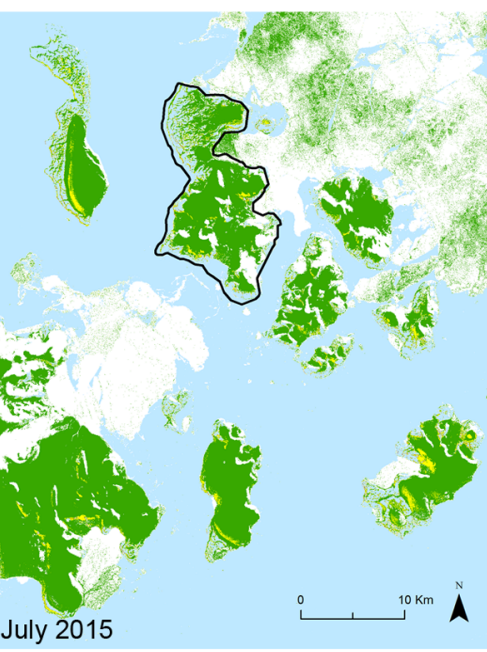

July 2015

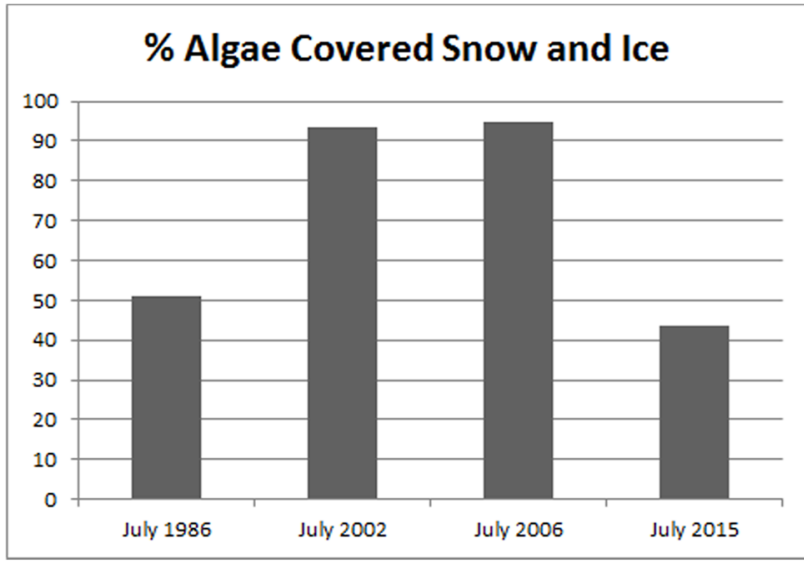


Figure 2 (on next page)

Abundances of microbes in red snow and white snow samples

(A) Abundances of viruses, Bacteria and Eukaryotes in samples from red snow and snow communities. The y-axis shows abundances after normalizing and standardizing raw read counts to ensure cross-sample comparisons are valid. (B) Bar plots showing abundances of two Eukaryotic phyla found in red snow and snow communities. Chlorophyta is the phylum that contains the genus Chlamydomonas. 



\section{Figure 3 (on next page)}

Functional pathways in red snow and white snow

(A) Bar plots showing functional pathways that were statistically significantly different in abundance between red snow and snow. (B) Bar plots depicting energy metabolism pathways and their abundances in red snow and snow. 
Figure 4 (on next page)

Model of red snow microbiology

Model of $C$. nivalis in white and red snows. The left panel shows several microbial communities that are found in white snow. Sunlight promotes astaxanthin expression in $C$. nivalis, turning the snow to red and promoting community metabolism shifts through stimulation of heterotrophic metabolism. The $C$. nivalis blooms, albedo is decreased and local snow and ice melts at a faster rate (right panel). 


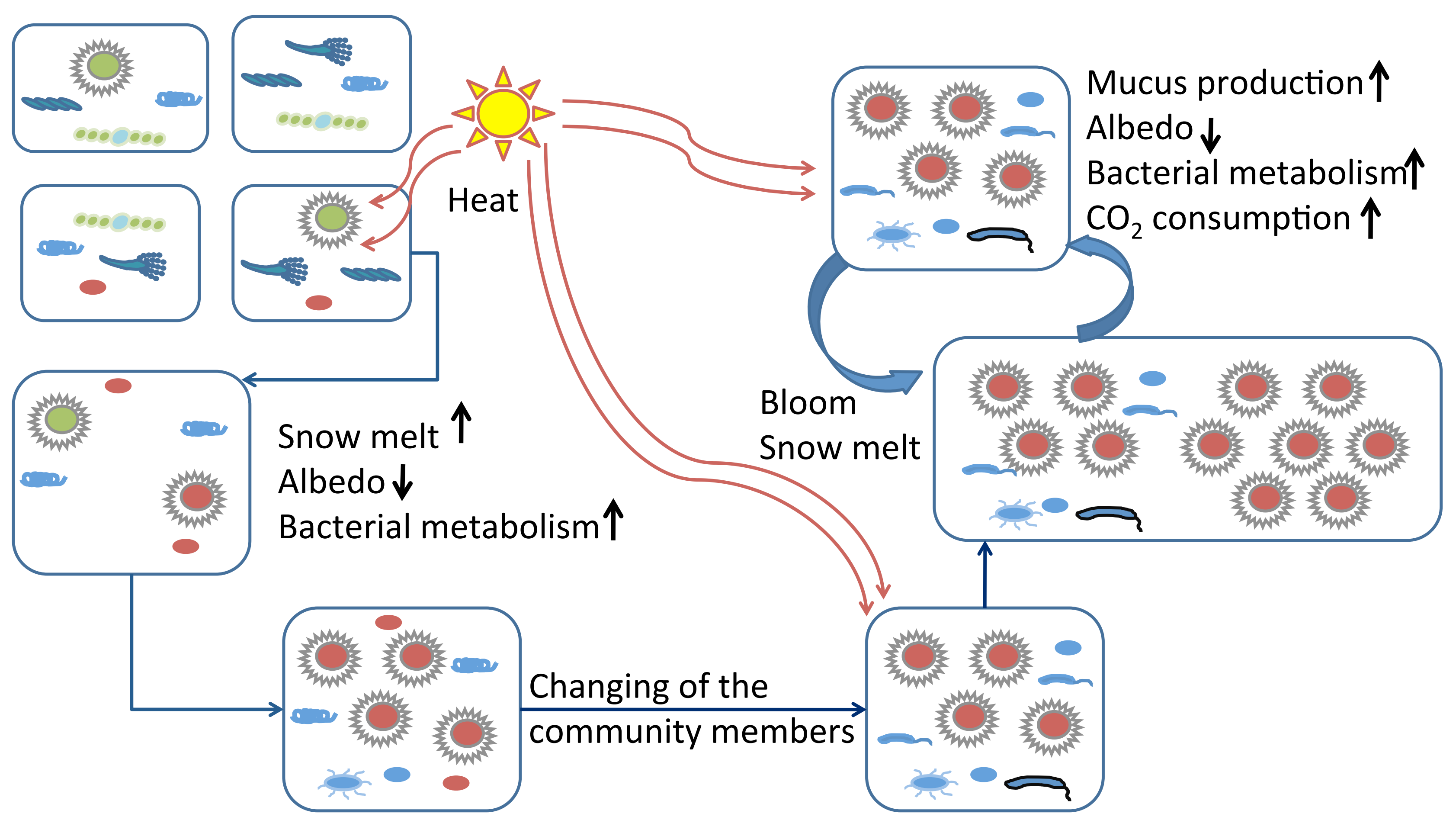

Aspergillus

Neurospora
C. nivalis

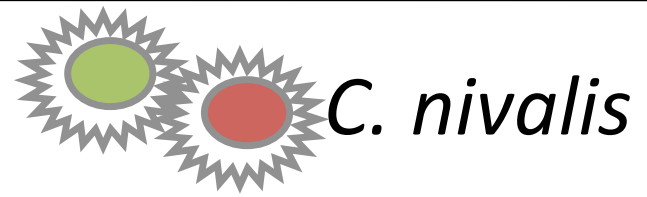

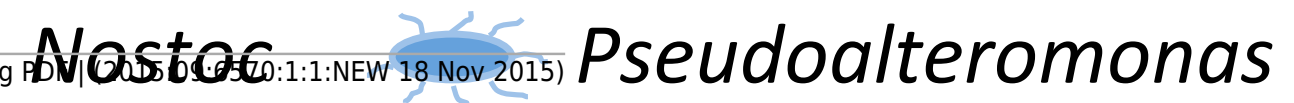

Alteromonas

$\overbrace{\text { Vibrio }}$

ars Spirosoma 